\title{
The Test of Time: Human and Cosmic Time
}

\section{Abstract}

The ultimate project of Bergsonism is to find a 'living unity' that welcomes life, consciousness, and the material universe. But it proves difficult for this philosophy, which starts from the experience of conscious life and takes the immediate data of consciousness as its guiding principle, to connect our subjective and private psycho-vital experience to the 'objective' and common reality of the universe. In fact, the very concept of the material universe is heavily saturated with intellectual representations that leave no room for a 'living unit'. It is precisely at this level that the debate between Einstein and Bergson gains importance. From Bergson's point of view, there is no way to grasp the real nature of time but by living it; we can only start from the intuition we have of our own conscious, lived experience. In this paper we want to show how Bergson constructs a 'plane' of nature - that is a plane of light - that connects the duration of the universe to the duration of the self. A plane in which nature is understood as the univocal feuilletage of durations that we experience: nothing more nor less than the unity of spirit, life, and matter

\section{Science and Philosophy: Two Different Methods}

For Bergson, the relationship between science and philosophy is essential. Science is not second or secondary. It has its own method, different from that of metaphysics, and its own kind of precision. In The Creative Mind, Bergson says that science touches the absolute and then, the real. But this was not a new thesis. Bergson had already expressed it in Creative Evolution:

Positive science, indeed, may pride itself on the uniform value attributed to its affirmations in the whole field of experience. But, if they are all placed on the same footing, they are all tainted with the same relativity. It is not so, if we begin by making the distinction which, in our view, is forced upon us. The understanding is at home in the domain of unorganised matter. On this matter human action is naturally exercised; and action, as we said above, cannot be set in motion in the unreal. Thus, of physics, - so long as we are considering only its general form and not the particular cutting out of matter in which it is manifested - we may say that it touches the absolute. On the contrary, it is by accident - chance 
or convention, as you please - that science obtains a hold on the living analogous to the hold it has on matter. Here the use of conceptual frames is no longer natural. I do not wish to say that it is not legitimate, in the scientific meaning of the term. If science is to extend our action on things, and if we can act only with inert matter for instrument, science can and must continue to treat the living as it has treated the inert... But, in doing so, it must be understood that the further it penetrates the depths of life, the more symbolic, the more relative to the contingencies of action, the knowledge. On this new ground philosophy ought then to follow science, in order to superpose one scientific truth a knowledge of another kind which may be called metaphysical [Thus combined, all our knowledge both scientific and metaphysical, is heightened]. In the absolute we live and move and have our being. The knowledge we possess of it is incomplete, no doubt, but not external or relative. It is reality itself, in the profoundest meaning of the word, that we reach by the combined and progressive development of science and of philosophy (Bergson 1922, 209-210).

Let us take up Bergson's arguments again: what is interesting about science is not its uniform approach to both physical matter and other kinds of objects (life, living beings, consciousness, and spirit). What is usually seen as an advantage (science's generality) becomes, for Bergson, a defect. Science does not really grasp life or spirit starting from matter and therefore its knowledge is merely relative. Science treats objects as unreal phenomena. Yet it succeeds in one area: that of action on matter. At this level, science even touches reality, grappling with it even if through mathematical and geometrical formulas. In fact, intelligence - science's organum/instrument - cannot be unreal since, for Bergson, it is, properly speaking, action on the real. So, in its general form, science 'touches the absolute', although in its detailed form it forgets time - real time, which is duration - considering only space. Intelligence, then, is not only symbolic or artificial: it has access to the real. Intelligence only become symbolic when it leaves the sphere of action on matter and tries to understand life, living beings, consciousness and spirit, all of which it considers to be inert.

Symbolic, for Bergson, means conventional and relative. But if intelligence is symbolic it is because it is weighed down by the need to act. Intelligence has to organise our action in the world and, therefore, it cannot take change and duration into account. One can act only by leaning on what is fixed, motionless, and not on what is continuously becoming. Nevertheless, Bergson does not consider science and philosophy to be in opposition; instead, he assigns philosophy the task of grasping that absolute which science can only touch symbolically. Philosophy, in fact, can touch the absoluteness of non-material objects (life, consciousness, God), building true metaphysical knowledge. And this is why Bergson makes Saint Paul's famous assertion from the Act of the Apostles, 'In God we live and move and have our being' the key concept of his philosophy - on condition, of course, that 'we replace "God" with the "Absolute"' (Bergson 1911, 210). Indeed, from the point of view of the Absolute wherever we are, we are 
in Being and not, as Kant argued, at a distance from it, that is, we are within the unknowable 'thing in itself'. For Bergson, matter, life, consciousness and supraconsciousness are all forms of being, absolutely speaking.

In order to respond to those who accused him of having devalued the role of science in Creative Evolution - for example, Julien Brenda and Bertrand Russell, who were perhaps his most virulent critics - Bergson restated his theses in the second part of the introduction to The Creative Mind, repeating once again that science can also touch an absolute. In a way, then, his 1922 book only clarifies the position he first took in Creative Evolution in 1907. In 1922, Bergson says that the sciences are no less precise than philosophy and this is why it is not even necessary to reject physics in its 'general form' as Creative Evolution did. Instead, it is necessary to outline the precise contours of intelligence because this also touches on the very structure of matter, a fact that modern trends in science continue to confirm:

when we bring the intellect back to its precise contours and when we delve deeply enough into our sense impressions so that matter begins to surrender to us its inner structure, we find that the articulations of the intellect apply exactly to those of matter. I therefore do not see why the science of matter should not reach an absolute (Bergson 1946, 44).

That science and metaphysics both touch the real absolutely, although by applying two different kinds of precision, is one of the essential points of Bergson's philosophy. But what does it mean to say that science touches the absolute? To maintain that science touches the absolute means that science is no longer the set of laws governing the phenomenal world as Kant thought, but instead coincides with a level of reality, namely the reality that extends itself in and as space. Intelligence is directly concerned with this extended reality (in Creative Evolution, Bergson had already stated: 'Matter or mind, reality has appeared to us as a perpetual becoming' - Bergson 1922, 287).

Yet, by affirming this, Bergson is not according scientific knowledge superior value, nor is he putting science and philosophy on the same plane. While being critical of the sciences, Bergson constantly includes scientific approaches in his analyses. Nonetheless, he always distinguishes between the methods of science and philosophy as two different ways of approaching the same reality. Not because one is real and true, while the other is fictious and artificial. In order to remove any ambiguity from his discourse, and to avoid being accused of irrationalism, Bergson often insists that intelligence is not a pure abstraction: it apprehends a part of reality itself, because both science and metaphysics deal with the real absolute. Science, in sum, does not distort its object, it is not pure constructivism. 
Yet, if science touches a material absolute, namely an absolute that is extended in space, metaphysics touches an absolute which lasts and takes time. Thus, it is clear that Bergson challenges Kant in two ways. First, he reinstates the possibility of metaphysics; second, he denies science's dependence on the relativity of knowledge: 'I reject the arguments advanced by philosophers, and accepted by scholars, on the relativity of knowledge and the impossibility of attaining the absolute' (Bergson 1946, 41). This leads to a double benefit: metaphysics becomes possible and science is not phenomenal. Both of them return to reality itself and can be absolute.

Let us now examine the scientific method of precision, starting from Bergson's distinction between two types of reality: evolutionary and material.

\begin{abstract}
Radical indeed is the difference between an evolution whose continuous phases penetrate one another by a kind of internal growth, and an unfurling whose distinct parts are placed in juxtaposition to one another [...] It is true that alongside the states of consciousness which live this unshrinkable and inextensible duration, there are material systems which time merely glides over. Of the phenomena which follow from them one can really say that they are the unfurling of a fan, or better still, the unrolling of a cinematographic film. Calculable ahead of time, they existed prior to their realization in the form of possible (Bergson 1946, 19)
\end{abstract}

In some cases, nothing can be accelerated without changing the very nature of reality; in others, acceleration changes nothing - a film, for example, where the speed of its unwinding has no consequences for the content. One might think that Bergson here considers all material systems to be timeless: 'Does the material universe in its entirety form a system of this kind?' (Bergson 1946, 19). But this is not the case; the question is only a methodological artifice: 'When our science assumes this, it simply means by so doing to discard everything in the universe which is not calculable' (Bergson 1946, 19). Science measures space, it does not take time into account; it eliminates time to better take space into account. Science always moves towards the spatial and material dimension of things. But the philosopher

who does not want to discard anything is really obliged to ascertain that the states of our material world are contemporaneous with the history of our consciousness. As the latter endures the former must be bound in some way to real duration (Bergson 1946, 19).

Thus, the method of philosophy is not at all the same as that of science: it takes into account the whole of experience, leaving nothing aside (metaphysics is an integral experience). More specifically, philosophy connects external things to lived durations, the material universe to consciousness. It seeks duration in those realities that are different from consciousness and finds that they also en- 
dure, taking part in duration. Consciousness, in fact, is not isolated. Yet, if it lasts, the other realities, life and the universe, which act upon consciousness, must also last. In this regard the example of the glass of sweet water used in Creative Evolution and taken up in The Creative Mind, is very important.

Let's take up the argument from Creative Evolution. Bergson starts by commenting on the dream that inspires modern science: to get as close as possible to the state of an intelligence that could embrace in a single mathematical formula the totality of the forces that make up nature and the variety of the situations of the beings that populate it. Bergson sums up this project for us: 'The essence of mechanical explanation, in fact, is to regard the future and the past as calculable functions of the present, and thus to claim that all is given' (Bergson 1922, 39-40). This idea, 'all is given', does not involve time. Bergson has already shown many times that between two times, $t$ and t', science does not deal with the interval but only with its extremities. This interval, in fact, could slow down infinitely or conversely take on an infinite speed, but nothing would change in the scientist's formulas and results.

Science doesn't really take duration into account: it only takes the relations, the juxtaposition of the parts into consideration, firmly believing that 'time doesn't bite'. Scientific time is mathematical and excludes duration, considering only the simultaneous definition of each position of a system's parts. But then, how can we understand succession in the physical world? And, besides, is there even succession in the physical world? Or in the universe? Unquestionably, answers Bergson: 'Succession is an undeniable fact, even in the material world' (Bergson 1922, 10). Yet, succession or history in the universe cannot be explained starting from isolated systems carved out by intelligence: 'this history, in point of fact, unfolds gradually, as if it occupied a duration like our own' (Bergson 1922, 10). For Bergson any succession proves that something is happening, that something new is being produced.

[I]f the future is bound to succeed the present instead of being given alongside of it, it is because the future is not altogether determined at the present moment, and that if the time taken up by this succession is something other than a number, if it has for the consciousness that is installed in it absolute value and reality, it is because there is unceasingly being created in it not indeed in any such artificially isolated system as a glass of sugared water, but in the concrete whole of which every such system forms part, something unforeseeable and new (Bergson 1922, 358-359)

The famous example of the sugar in the water glass now becomes clearer. It is an experiment that links two types of reality: 'If I want to mix a glass of sugar and water, I must, willy-nilly, wait until the sugar melts' (Bergson 1922, 10). This means that a time that is different from mathematical time immediately erupts: 
it is the time of my waiting, of my impatience. It is no longer a thought or a conceptual time; no longer a set of relationships. Sugar's time is lived because, although sugar dissolving in water seems to be a physical event independent of me, this event has an absolute meaning for me. Waiting translates into 'a certain portion of my own duration, which I cannot protract or contract as I like’ (Bergson 1922, 10) - once again the problem of acceleration!) and for Bergson this 'other' time immediately manifests itself: sugar dissolves in water through a chemical process, but this event, as simple as it is banal, highlights a creation upon which my consciousness inevitably stumbles. Something is happening: an unpredictable event, a duration that is also unique in the universe. Sugar therefore does not only dissolve chemically: it has a duration that must be linked to the duration of the Whole because, for Bergson, as soon as we integrate a physical system into the Whole, its own duration becomes evident. Why precisely at that moment? Why does Bergson allow himself to attribute duration to each physical system, that is to say a form of existence analogous to ours, as soon as it becomes part of the Whole?

Bergson says: 'There is no reason, therefore, why a duration, and so a form of existence like our own, should not be attributed to the systems that science isolates, provided such systems are reintegrated into the Whole' (Bergson 1922, 12). This is the case because melting sugar is not an isolated phenomenon. It is true that science tends to understand matter geometrically and to artificially represent isolated systems in order to better capture the characteristics of extended matter. But even the smallest system is nested within, is linked to, external influences, such that we can go back through these threads to the entire universe, 'in which we live the duration immanent to the whole of the universe' (Bergson 1922, 11). Every part of the universe links us to the Whole. And it is this Whole that is at work in every single system, right down to the glass of water, and that makes itself felt in the very duration of my expectations of what is going to happen. Thus, for Bergson the duration of each physical system is no longer a mystery: it coincides with the creative movement of the Whole through each of its parts, that is with the pulsation of the Whole in each of its systems, which are only conceptualised as isolated units by science. Each duration, in fact, is the emanation of the duration of the Whole and Bergson, therefore, can conclude that 'the universe endures' (Bergson 1922, 11).

After having discovered duration at the core of psychological life, Bergson makes it the stuff of the entire universe. The latter creates forms and continuously elaborates something absolutely new: 'The duration of the universe must therefore be one with the latitude of creation - which can find place in it'(Bergson 1922, 359). This is why, in Bergson's opinion, the methods of science and philosophy should not be fully separated. In the physical universe studied by scien- 
ces, it is true that no duration or creation can be detected, because science freezes time to focus on space, that is, in order to act. The work of science consists in isolating parts of the Whole as closed material systems, so as to better decompose them in space. But the work of the philosopher consists, on the contrary, in returning these to the Whole, starting from our experience of 'it'. Philosophy, in short, reintegrates a fragmented physical system into the Whole and grasps its relation to duration. But it can do this only by connecting the universe as a whole to our duration. Our perception, in fact, isolates closed systems as does our science. But, apart from science and its need to plan action, these closed systems are not isolated. They are isolated for science only. In reality, they are connected with a living body capable of 'marking out upon matter the design of its eventual actions even before they are actual' (Bergson 1922, 12).

For Bergson natural perception and science tend to delimit and close, fragment and geometrise because they are based on preparation for action. But, when they are 'repositioned' in the universe of interactions, these closed systems reveal their own durations:

What else can this mean than that the glass of water, the sugar, and the process of the sugar's melting in the water are abstractions, and that the Whole within which they have been cut out by my senses and understanding progresses, it may be in the manner of a consciousness? (Bergson 1922, 10)

The Creative Mind closely follows the relationship between the closed systems of science and the whole of the universe. Now, science has to build 'material systems in which time only slides' - astronomy, chemistry, physics are cited (Bergson 1946,19 ) - by extending the role of natural perception (facilitating action by producing static images). But the experiment with the glass of sugar water shows that 'if one can cut out from the universe the systems for which time is only an abstraction, a relation, a number, the universe itself becomes something different' (Bergson 1946, 20). Thus, 'if we could grasp it in its entirety, inorganic but interwoven with organic beings, we should see it ceaselessly taking on forms as new, as original, as unforeseeable as our states of consciousness' (Bergson 1946, 20). We can see the significance of this statement: the universe also creates forms, has an unpredictable history, namely a form of duration. Yet, it is above all the method that is important: in order to reveal the action that duration has on the other durations (life, universe, even the naturans principle of all nature), we must always start from it, and from our experience of it. 


\section{The Whole Is of the Same Nature of the Self}

In sum, Bergson contends that we must not confuse the work of science with that of philosophy. The latter has to return to the real, moving, time which is at the heart of things, life, and consciousness. Starting from his own conscious experience, a philosopher finds duration in all things, because for Bergson each consciousness, as far as it is duration, takes part in a universe that lasts (Matter and Memory) and in our lived lives, life being a vital impulse - élan - which is another name for duration (Creative Evolution). Yet, this method involves a difficulty related to the very nature of direct and psychological experience: to understand how the material universe is also a form of duration. For a philosophy which starts from the experience of conscious life and takes what our experience immediately attests to as merely a guideline, it becomes in fact very tricky to connect psycho-vital experience to the material universe. And please note that this difficulty does not only face Bergsonism. It raised questions for all the $19^{\text {th }}-20^{\text {th }}$ century philosophies of nature (Nietzsche, Whitehead, Tarde), which tried to deal with the question of cosmological unity and the nature of matter.

In the western philosophical tradition, the concept of matter has been saturated with intellectual representations that prevent its insertion into the 'living unity' of the cosmos. Thus, it is not surprising that Bergson considered one of the most important issues in Creative Evolution to be the fact that the material universe has the same nature as the self: duration. Speaking at the French Philosophical Society in 1908, he explained that one of the objects of Creative Evolution is to show that 'le Tout est [...] de même nature que le moi, et qu'on le saisit par un approfondissement de plus en plus complet de soi-même' (Bergson 1972, 774). The last part of the sentence is important because it reveals the meaning of Bergson's philosophical method: from the self to the whole, from inner conscious experience to what is involved in this experience (other durations).

The renovation of the concept of matter began in Matter and Memory, a book focusing on our relationship to the universe. Here, Bergson claimed that the brain, if isolated, does not produce anything, neither interiority nor thought. Only the relationship between the living body and the world can explain the mechanism of perception together with its connection to pure perception, which encompasses the whole flow of the universe. For Bergson our perception does not create things nor images: it merely produces the static images needed for bodily actions, images selected from the flow of the universe. Perception, then, is linked to the universe, and Creative Evolution continued this meditation. At any rate, this is what Bergson said to the Philosophical Society on August 8, 1908, comparing his reflections to those in Matter and Memory 
Dans le premier de ces deux livres, on montre que l'objectivité de la chose matérielle est immanente à la perception que nous en avons, pourvu qu'on prenne cette perception à l'état brut et sous sa forme immédiate. Dans le second, on établit que l'intuition immédiate saisit l'essence de la vie aussi bien que celle de la matière (Bergson 1972, 774)

Philosophy challenges science exactly because it studies the essence of matter. In philosophy, 'l'acte de connaissance coïncide avec l'acte générateur de la réalité' (Bergson 1972, 774) - and to grasp the essence of matter means to grasp it exactly by means of the generating act that produces it. Nevertheless, from the point of view of method, philosophy can only exploit the intuition we have of our experience of conscious life.

In Matter and Memory, our intuitive participation in the universe becomes evident. But Creative Evolution does not require us to change method: we can move from 'immanent to the whole of the universe' (Bergson 1922, 11) only by starting with ourselves, from our existence.

\section{The Tendency of Modern Science to Dematerialise Matter}

If science understands matter with the help of mathematical laws, should we think that matter is reduced to these laws, and can only be composed of immobile stable elements? Bergson, always on the lookout for new horizons in science, sees another path at the very heart of physical theories. Matter and Memory was inspired by electromagnetism and draws lessons from Thomson and Faraday: 'psychological analysis has already revealed to us that this discontinuity is relative to our needs: every philosophy of nature ends by finding it incompatible with the general properties of matter' (Bergson 1947, 266). Science itself thus encourages us to see matter only as 'modifications, perturbations, changes of tension or of energy, and nothing else'(Bergson 1947, 266).

In Matter and Memory, Bergson does not forget to quote Maxwell, who as early as 1864 showed that light is an electromagnetic waveform (see Davies 1988, 32). Even though we had to wait until 1924 before particles of matter such as electrons were considered to have wavelike properties and to listen to scientists talking about waves in matter, the fact remains: ever since, atomic matter has been dissolved in immaterial fields of force. Electromagnetic science is still present in Creative Evolution, as can be seen from the references to Faraday's use of X-rays to penetrate the atom, the discovery that every atom 'fills the world' and, more generally, the idea of force fields (see Davies 1988, 67; Nottale 1997, 34). Again, Bergson tells us that science, as well as consciousness, makes us un- 
derstand that a material point is 'a mere view of the mind' (Bergson 1965, 41). Electromagnetic physics, in fact, confirms that solid bodies are not primary, that matter is first waves and light, indivisible energy, and continuous flow. Consequently, there is no gap between what consciousness reveals to us and what science tends to show: 'Science and consciousness are agreed at the bottom' (Bergson 1947, 260).

In Creative Evolution, Bergson stated that 'the more physics advances, the more it effaces the individuality of bodies and even of the particles into which the scientific imagination began by decomposing them: bodies and corpuscles tend to dissolve into a universal interaction' (Bergson 1922, 168). Yet, he would later say this again, in the second introductory essay of The Creative Mind, where he shows that, although science has served as a vector for this movement, it did not follow it to its logical end, because of its own conventions: 'When I began to write, physics had not yet made the decisive advances which were to bring a change in its ideas on the structure of matter' (Bergson 1946, 83). He went on to add:

Sooner or later, I thought, the idea of support would have to be abandoned [...] Sooner or later, I thought, physics will be brought around to the point of seeing in the fixity of the element a form of mobility. When that time came, it is true, science would probably give up looking for an imaged representation of it, the image of a movement being that of a moving point (that is to say, always of a minute solid) (Bergson 1946, 83-84).

The fusion between the wave and the corpuscle is again evoked: a fact that could make us think that a piece of iron is a melodic continuity more than a thing. By necessity, 'the great theoretical discoveries of recent years have led physicists to suppose a kind of fusion between the wave and the corpuscle, between substance and movement, as I should express it' (Bergson 1946, 84). Yet, this text from the second introduction of The Creative Mind also refers in a note to the essay The Perception of Change, which makes the point even clearer. Here, in fact, Bergson asked himself: doesn't science dissolve matter and each moving thing by making us sense a physical movement? To which he answered:

A suggestion of this vision of material things already comes to us from physical science. The more it progresses the more it resolves matter into actions moving through space, into movements dashing back and forth in a constant vibration so that mobility becomes reality itself. No doubt science begins by assigning a support to this mobility. But as it advances, the support recedes; masses are pulverised into molecules, molecules into atoms, atoms into electrons or corpuscles: finally, the support assigned to movement appears merely as a convenient schema, a simple concession on the part of the scholar to the habits of our visual imagination (Bergson 1946, 174). 
Finally, there are no more things in movement: their supposed movement has become a 'movement of movements' (Bergson 1946, 83). By stressing the triumph of the wave over the corpuscle, in these passages, Bergson is basically saying that matter radiates. And what is the meaning of a universe of light, if not that of being a universe that lasts and expands, a universe of energy to which we are necessarily connected? And why is this so important for a theory of nature? Because this matter is also a form of duration and movement, as we have just seen: the example of the glass of sugar water showed us that the material universe does not change without us perceiving it changing, and without us perceiving ourselves being transformed. The durations of the universe and ourselves are therefore intertwined.

To recap, we can say that Bergson followed science's developments and discoveries because modern science tends to dematerialise matter. It is true that science still uses spatializing images, the necessary work of intelligence being to spatialize, but it is clear that even in science, the tendency is to do without such images as much as possible. In any case, the philosopher who understands what duration is for, by having explored it in his psychic life, can only be interested in this kind of science. It proves that matter cannot be reduced to pure stability although it cannot demonstrate this fact by itself. Science, in fact, is not philosophy and Creative Evolution has shown that the limits on science following this movement so as take the dematerialisation of matter to its extreme consequences are due to the natural infirmity of its proper organum: intelligence. The latter always cuts matter, always divides it, because it is not made to go back in time, but rather to act on matter.

Therefore, the constitution of closed systems is the essence of the work of physics. By holding that matter is 'decomposable into isolated systems', writes Bergson, 'in attributing to it quite distinct elements which change in relation to each other without changing in themselves (which are displaced shall we say, without being altered), in short, in conferring on matter the properties of pure space' (Bergson 1922, 214-215), science accentuates the spatiality of matter and thus sets limits on its own work of dematerialisation. Philosophy, on the contrary, seeks to go to the end of this dematerialisation by wresting matter back from spatializing intelligence. For philosophy, in fact, matter is a form of duration. But how can we explain why intellectuality and materiality are nevertheless so well adapted to each other?

In Creative Evolution, Bergson reflects on the vital genesis of our psychological frameworks for knowledge, concluding that there is no philosophical reason to set intellectuality and materiality in opposition as has been the case in most philosophies. Why, in fact, does the world obey our mathematical principles? Why is the world knowable? Knowledge would be a miracle if we had had to ad- 
dress a kind of matter that was totally foreign to our intelligence or address it with an intelligence that was totally foreign to matter. The intellect and materiality have to communicate because 'this matter, in all that it has that is intelligible, is our own work!' (Bergson 1922, 216). For Bergson, in particular, spatialized matter is the product of the work of intelligence and intelligence is the product of the work of life. Life produces intelligence to master matter, and this reciprocal genesis of materiality and intellectuality makes us understand why matter is spatialized and why it is always immobilised in our intellectual and scientific representation. Matter, says Bergson, inevitably accentuates 'its materiality, when viewed by the mind' (Bergson 1922, 213).

Yet, to say that materiality derives from intellectuality is to confirm the Kantian thesis of the ideality of space. Our intelligence is certainly a spatial shaping of the world, but it is so for vital reasons that Kant did not grasp. His mistake, according to Bergson, is to have assumed that 'space is given as a ready-made form of our perceptive faculty, a veritable Deus ex machina, of which we see neither how it arises, nor why it is what it is rather than anything else' (Bergson 1922, 216). On the other side, to operate the vital genesis of intelligence is to assign it a function by refusing it as an absolute: spatialization serves action. This is why, in the end, science works in the direction of materiality and not in the direction of duration. Indeed,

[i]t is impossible to consider the mechanism of our intellect and the progress of our science without arriving at the conclusion that between intellect and matter there is, in fact, symmetry, concord and agreement. On one hand, matter resolves itself more and more, in the eyes of the scholar, into mathematical relations, and on the other hand, the essential faculties of our intellect function with an absolute precision only when they are applied to geometry (Bergson 1946, 43)

But this spatialization of matter prevents us from grasping the duration that remains within it. Fully intellectualised, matter becomes spatialized and geometrised, without action, movement, or energy. It is an extended and unfolded kind of matter. All of its parts are therefore divisible and separable ad infinitum. Nothing is transformed within it: this kind of matter has only relative movements (as in Cartesian and Galilean mechanics). We may add that such intellectualised matter is continuous, but only in the sense of mathematical continuity: the abstract possibility of infinite division. But, in reality, this abstract continuity does not allow for continuity of movement to the extent that it exactly underpins the discontinuity necessary for action. In fact, we always find ways to redefine discontinuity, because of these needs, and therefore we always postulate - and thus find - atoms, points, grains, lumps, bodies, and other things with spatial extension. Hence Bergson's well-known thesis: intelligence only represents disconti- 
nuity on a background of ideal and mathematical continuity (Bergson 1946, 221222).

For Bergson there is no point in considering atomism and geometrism as opposites, given that the two work together: the ideal division of space provides fixed points for action. This means that matter is never as completely spread out in space as our intelligence and senses represent it: although it spreads out in the direction of space, matter is not space. This double-line explanation recalls the one describing sugar in a glass of water: just a little 'attention' to this matter, which at first seems spatial to us, suffices to make us feel the 'action of the Whole' (Bergson 1922, 219) within it. Thus, science itself puts us on the path to a matter that cannot be reduced to pure space. Yet, it is the task of philosophy to broaden this trend of science by grasping it within a wider experience that includes our own duration. Within it, in fact, we can understand that there is also movement without mobility in matter and a movement of the universe, which has its own history.

\section{Energy Degradation}

A second important way in which Bergson refers to physics in Creative Evolution concerns the second principle of thermodynamics. Bergson wants to show the slope of the universe towards space. Just as electromagnetism shows us the reality of physical motion, just as a glass of sugar water connects us to the duration of the universe, thermodynamics shows us the reality of that movement which is the extension of the universe. The second principle of thermodynamics affirms that an isolated system progressively and irreversibly converts its potential energy into an equipotential structure. Thus, according to Bergson, it confirms the tendency of the material universe towards spatialization. To spatialize now means to pass from a difference in potential to a homogeneous structure. And the universe, if it is assumed to be closed, energetically evolves by tending towards entropy. This is why the second law of thermodynamics appears to Bergson as 'the most metaphysical of the laws of physics' (Bergson 1922, 256). Moreover, it indicates the direction in which the universe is moving, namely the uniform distribution of energy: 'is seen to be ever exhausting something of the mutability it contains' (Bergson 1922, 257).

Therefore, we find that once again physics allows us to escape from the relativity of movement. But how can we account for this trend? For Bergson, the lesson of thermodynamics remains meaningless if we don't relate it back to our own experience. In fact, even with respect to entropy, the attestation of our conscious life experience is crucial. The scientist who sticks to matter does not aim to ex- 
plain how consciousness, life, and the universe communicate and relate to each other. What philosophy brings, on the contrary, is the intuition that the essential mutability of the world cannot have its source within matter itself. If matter has a tendency towards spatialization, how could it be the creator of energy? For Bergson, we can only interpret this entropic fall by confronting it with our psychovital experience, that is by connecting it to our existence, to our experience of duration. If we can understand it, in other words, it is because we can see that the universe does not last in the same way that our life and our consciousness do.

Yet, the scientist cannot understand it, having cut himself off from part of the experience. So, according to him, the direction of the initial mutability towards stability is physically explainable, although the eruption of energy that conditions this mutability will never be so: he may suppose an infinite universe at the beginning, but he will never bring forth energy from this infinite universe. According to his definition of matter, in fact, such a universe would be precisely a universe spread out with material elements that are absolutely external to each other: a universe without tension, relation, and potential. 'In reality, the problem remains insoluble as long as we keep on the ground of physics' (Bergson 1922, 258) says Bergson. In other words, when he wants to explain the presence of energy, the physicist will not look for any kind of extra-spatial energy of which he has no concept. But the philosopher sees it at work in every moment of life and, above all, in his living conscious experience.

The physicist does not believe that any sort of extra-material energy can exist. Thus, he will stick to the definition of matter he has just given, namely matter as a slope towards uniformity and stability. The philosopher will instead point out that there is a distinction between extra-material creation and material conservation, between open and closed, between philosophy and science. But how can we establish this distinction if we abstract from our experience of being a duration intersecting with other durations? Let us insist on this point of method: the fact that the universe radiates and falls towards entropy cannot be understood other than by starting from our duration and the way it implies the duration of the universe (the glass of sugar water). Thermodynamics, in fact, leads us to think that the universe has a direction or an extra-spatial primordial energy that only later will fall back into space.

\section{The Intricacy of Durations}

Bergson does not posit the universe as an objective, all-encompassing framework that precedes us. The universe is neither fixed nor unchanging. The uni- 
verse is deduced from our perception, from what is transformed and sensed in our conscious life experience. We don't change without things changing, the world doesn't change without our knowledge of this change, because life, matter, and consciousness are durations, and there is communication between all of these durations. Our perception - here synonymous with intuition - is in itself only a relation between durations. We perceive the material world, as one reads in Duration and Simultaneity,

and this perception appears, rightly or wrongly, to be inside and outside us at one and the same time; in one way, it is a state of consciousness; in another, a surface film of matter in which perceiver and perceived coincide. To each moment of our inner life there thus corresponds a moment of our body and of all environing matter that is "simultaneous" with it; this matter then seems to participate in our conscious duration (Bergson 1965, 45)

Duration and simultaneity even goes so far as to say that we live a cosmic life as much and more than an individual life (Bergson 1965, 51). Then, it is not by chance that, in The Creative Mind Bergson uses the example of colours being wavelengths to get the point across. Here Bergson proposes an experiment that consists in imagining ourselves as a colour and wondering whether we might not be immediately connected to the durations of other colours.

But just as a consciousness of colour, which would harmonise inwardly with orange instead of perceiving it outwardly, would feel itself caught between red and yellow, would perhaps even have, beneath the latter colour, a presentiment of a whole spectrum in which is naturally prolonged the continuity which goes from red to yellow, so the intuition of our duration, far from leaving us suspended in the void as pure analysis would do, puts us in contact with a whole continuity of durations which we should try to follow either downwardly or upwardly: in both cases we can dilate ourselves indefinitely by a more and more vigorous effort, in both cases transcend ourselves. In the first case, we advance toward a duration more and more scattered, whose palpitations, more rapid than ours, dividing our simple sensation, dilute its quality into quantity: at the limit would be the pure homogeneous, the pure repetition by which we shall define materiality. In advancing in the other direction, we go toward a duration which stretches, tightens, and becomes more and more intensified: at the limit would be eternity (Bergson 1946, 220).

The Creative Mind clearly defends the thesis of the co-implication of durations each one involving the other. Our experience of conscious life, in fact, implies a relationship to the duration of the universe, that is to another experience of conscious life. Moreover, it also bears witness to a more contracted or more intense duration, which would, at the limit, be the 'eternity of life' (Bergson 1946, 220): a pure and free creativity where our own duration, Bergson says eloquently in the same text on colours and durations, 'would find itself like vibrations in light' (Bergson 1946, 220). Light even brighter than the visible universe, because 
it is the light of a true source. In relation to science, the philosopher's work is therefore to think about how things communicate, and for Bergson they can only communicate inasmuch as they are durations: movements that act mutually. In this regard, he writes in Creative Evolution:

The philosopher must go further than the scientist. Making a clean sweep of everything that is only an imaginative symbol, he will see the material world melt back into a simple flux, a continuity of flowing, a becoming. And he will thus be prepared to discover real duration there where it is still more useful to find it, in the realm of life and of consciousness. [...] So understood, philosophy is not only the turning of the mind homeward, the coincidence of human consciousness with the living principle whence it emanates, a contact with the creative effort: it is the study of becoming in general, it is true evolutionism (Bergson 1922, $390-391)$.

\section{Sympathy}

But how can we move in the direction of the duration of non-human things, that is in the direction of other durations? The notion of sympathy plays a prominent role here. Several times Bergson defines intuition as sympathy and his use of the term sympathy to describe the intuition of another reality is very significant. Intuition, considered as sympathy, becomes a movement of fusion towards otherness: 'For one does not obtain from reality an intuition, that is to say, a spiritual harmony with its innermost quality if one has not gained its confidence by a long comradeship with its superficial manifestations' (Bergson 1946, 235).

It is thus necessary to become familiar with the object, to acquire enough facts to 'melt' them into a unity that comes close to what the envisaged reality is. Only then can there be an intuitive leap from multiplicity to unity, from static to dynamic, from space to time. Sympathy is the means by which I begin to espouse the movement of the other reality I apprehend. And, by doing so, I can open myself to durations other than my own. This point is crucial. We do not only have an intuition of ourselves: we can also intuit a thought that is external to us and sympathise with it. Yet, for Bergson we can only do so starting from what has been inserted in language and concepts. In order to know another philosophy, for example, we are forced to start from the philosophical system that expresses it, from its sources, its similarities with others, its cultural environment. And it is only once this kind of impregnation, contact or effort has begun that we can grasp the essence of that philosophy by penetrating the system's real and simple intention. Thanks to intuition, in short, we no longer seek to 'go around' the system. We grasp its intuition intensively and no longer extensively. 
Bergson presents sympathy as a relationship between my duration and others. Sympathy is an effort to place myself in other durations, by placing myself in their movements. As we said, this is a crucial point because without this effort we would not be able to capture other durations. In other words, it is as if sympathy makes cosmology - the capture of durations in matter, life, and other spiritual realities - possible. It is, in fact, 'intuition of ourselves' (Bergson 1946, 35). Yet,

Between our consciousness and other consciousnesses the separation is less clear-cut than between our body and other bodies, for it is space which makes these divisions sharp. Unreflecting sympathy and antipathy, which so often have that power of divination, give evidence of a possible interpenetration of human consciousnesses. It would appear then that phenomena of psychological endosmosis exist. It may be that intuition opens the way for us into consciousness in general. But is it only with consciousnesses that we are in sympathy? If every living being is born, develops and dies, if life is an evolution and if duration is in this case a reality, is there not also an intuition of the vital, and consequently a metaphysics of life, which might in a case prolong the science of the living? [...] Let us go still further. Above and beyond the organizing process, unorganised matter appears as though decomposable into systems over which time slips without penetrating, systems which belong to the realm of science and to which the understanding can be applied. But the material universe in its entirety keeps our consciousness waiting; it waits itself. Either it endures, or it is bound up in our own duration. Whether it is connected with the mind by its origins or by its function, in either case it has to do with intuition through all the real change and movement that it contains [...] In short, pure change, real duration, is a thing spiritual or impregnated with spirituality. Intuition is what attains the spirit, duration, pure change. Its real domain being the spirit, it would seek to grasp in things, even material things, their participation in spirituality, I should say in divinity were I not aware of all the human element still in our consciousness, however purified and spiritualised (Bergson 1946, 35-36).

As we can see, the movement of sympathy leads us to an intuition that takes us out of ourselves, and beyond our humanity. It is an intuition of the vital, the material, and even the divine nature of the world. Each time we have an intuition, Bergson says, we grasp a real movement: a change which is an indivisible duration. All that lasts is a matter of intuition. And therefore, thanks to intuition we also understand the difference between matter and spirit, space and time. Now, science studies systems without time, proceeding to an increasingly fine analysis of their elements. But it always must be relayed by an intuition of what makes their movement and their capacity to change real, that is, by an intuition of what makes their vital impulse real: the duration of the universe. And please note that it is in this sense that Bergson speaks of a metaphysics of life: it is 'of' life because it takes the spiritual dimension of life into account. And, in 
the same way, he speaks of a metaphysics 'of' the material universe which captures the irreducible movement of the whole's duration. ${ }^{1}$

Let us note in passing Bergson's general interest in inter-psychological phenomena: interpenetration of consciences, psychological endosmosis. In 1900, Bergson took part in the foundation of the International Psychical Institute, and in 1909 he became a foreign correspondent for the Society for Psychical Research. Its aim was to study psychic phenomena such as telepathy, divinatory dreaming (telepathy and dreaming), spiritualist or mediumistic phenomena, the unconscious, and so on. When he became president of the Society for Psychical Research, he gave his lecture on Ghosts of the living. But the text of The Creative Mind on endosmosis is an excerpt from his lecture of 28 May 1913. Sympathy, in fact, is said to be similar to an endosmosis in which different durations mutually intermingle

\begin{abstract}
Let us not forget, moreover, that it is space which creates the sharp divisions. Our bodies are external to one another in space; and our minds, in so far as they are attached to those bodies, are separated by intervals. But if the mind is attached to the body only by a part of itself, we may conjecture that for the other part of the mind there is a reciprocal encroachment. Between different minds there may be continually taking place changes analogous to the phenomena of endosmosis (Bergson 1920, 86-87).
\end{abstract}

The essential thesis is that consciousness overflows the organism, so that what is to be explained are not these phenomena of communication between consciousnesses that go beyond bodies and their spatial situatedness. What remains to be explained is rather why they do not happen more often.

\title{
Conclusion
}

For Bergson, our intuitions or sympathy, open us to other durations and so we have to pay close attention to his notion of spiritualism. Spiritualism is not the entrenchment of duration in subjectivity, nor does it stand in contrast to science; on the contrary, it wins over nature, it invades nature, it concerns all beings. And it does so with the help of science. To intuit, in fact, means to reach the

1 At the end of the text, Bergson seems to regret that this intuition is not quite capable of carrying itself to the point in which the participation of things in divinity happens. Mystical experience, in fact, plays a key role in The Two Sources of Morality and Religion. For Bergson the mystics lead us in embracing natura naturans and it is for this reason that intuition, the mystic's organum, opens us up to a cosmology that is grasped not only purely in an interior and psychological sense. 
spiritual dimension of all beings. And so spiritualism is not synonymous with acosmism. Who emphasises the spirit does not move away from things or from the universe. Thanks to intuition one finds them again, touching them as truly as science does, but by another means, another vision, another method.

Spiritualism, for Bergson, means that a spirit or psyche is present in all realities of the actual world. Science and metaphysics, in fact, do not split the real, as if there were two distinct realities. They are two different points of view taken on the same real: space and time, but the real time, i.e., duration. This is why Bergson says that metaphysics is not 'the superior of positive science' (Bergson 1946, 48). Both embrace the same reality, and both do so absolutely; 'both touch the bottom of reality' (Bergson 1946, 41). In the same way, the realm of metaphysics is not purer, more complex, more delicate than that of science. Metaphysics grasps the same reality as science, but in a different way. Thus, spiritualism does not intend to flee from reality: it rather dwells within things. While science examines the material nature of things, metaphysics makes us understand that things also have another, spiritual dimension: duration.

Life, in short, is not only matter, it is duration too; the universe is not only mechanical, it also lasts. And it is within this framework that we must appreciate the debate between Einstein and Bergson and the meaning of Duration and Simultaneity. It is easy to understand that Bergson's aim was not to correct Einstein on a physical level nor to oppose a lived time to a physical time. For him, it was rather a question of finding, in physical time but beyond its measures, its immanent duration and, moreover, to find in this duration all the durations of the universe. For Bergson there is no single physical absolute time but a multiplicity of durations that are constantly weaving together and opening up to a new cosmology. And it is because the universe is duration that other durations can be grasped by contrast with it. Philosophy has to unfurl this implication in order to reveal a new cosmos.

\section{References}

Bergson, Henri (1920), Mind-energy. Lectures and Essays, New York.

Bergson, Henri (1922), Creative Evolution, London.

Bergson, Henri (1946), The Creative Mind, New York.

Bergson, Henri (1947), Matter and Memory, New York.

Bergson, Henri (1965), Duration and Simultaneity: with Reference to Einstein's Theory, New York.

Bergson, Henri (1972), Mélanges, Paris.

Davies, Paul (1988), Les forces de la nature, Paris.

Nottale, Laurant (1997), L'univers et la lumière, Paris. 
